\title{
Minimally Invasive Repair of a Delayed Recurrent Traumatic Cerebrospinal Fluid Rhinorrhea: A Case Report of Dislocation of the Bony and Dural Defects
}

Xiaofei Liu

University of South China

Ping Chen

The Second Hospital,University of South China

Bing Wang ( $\square$ wangb46@mail2.sysu.edu.cn )

Second hospital,University of South China

\section{Case Report}

Keywords: Cerebrospinal fluidrhinorrhea, Craniocerebral trauma, Recurrent, Minimally invasive repair

Posted Date: June 8th, 2020

DOI: https://doi.org/10.21203/rs.3.rs-32281/v1

License: (c) (1) This work is licensed under a Creative Commons Attribution 4.0 International License.

Read Full License 


\section{Abstract}

Background囚Dural and bony defects mostly occur in the same position in the cerebrospinal fluid囚CSF囚 rhinorrhea of anterior cranial base fractures, and a few cases of delayed CSF leakage after repair are also reported.

Case presentation $\varangle$ We report a case in which a pedicled temporoparietal fascial flap was used to repair the comminuted fracture of the anterior skull base with CSF leakage. Delayed CSF leakage occurred 45 days after the operation.A minimally invasive approach through an eyebrow incision was performed for reoperation, it was found that the bony defect was located in the right frontal sinus and the dural defect was located in the right ethmoid plate.

Conclusions:This case suggests that delayed traumatic CSF rhinorrhea after reconstructive surgery is more complex than usual,and appropriate approach should be adopted to repair the dural and bony defects, the transeyebrow approach is a good choice.

\section{Background}

Cerebrospinal fluid(CSF)rhinorrhea, commonly observed in anterior cranial base fractures,requires surgical treatment when conservative measures fail. Dural and bony defects mostly occur in the same position. Few cases of delayed secondary CSF leakage requiring surgical treatment are reported,dislocation of the bony and dural defects is rare. Due to the scarcity of such cases, limited data exist to guide the management of this complication. We have reported the case of a patient with a bilateral comminuted anterior skull base who underwent a first-stage craniotomy with pedicled fascial flaps. Despite this, the patient suffered delayed CSF rhinorrhea. During the second operation, it was found that bony and dural defects were not contiguous. The defects were repaired with a minimally invasive approach using multiple layers of free fat and fascia.

\section{Case Presentation}

\subsection{Patient Imformation}

A 33-year-old man was admitted for posture-related CSF rhinorrhea, which was prominent in lateral and head-down positions. 45 days ago, this patient was sent to emergency department with a consciousness disorder and a nasal leakage due to a fall injury after an electric shock. He also suffered from multiple skin burns on his limbs and perineum, with no significant past history. Continuous dynamic CT scan revealed an increase in bilateral frontal hematoma(Fig. 1). The GCS score dropped from 8 to 6 . Then he underwent bilateral craniotomy,bilateral temporoparietal fascia was used to repair the anterior skull base and the open frontal sinus was closed with bone wax. After the surgery, the patient's GCS improved, CSF rhinorrhea stopped without any intracranial infection. He was then transferred to the burn department for 
skin graft surgery. He then started to have posture-related CSF rhinorrhea and was transferred to neurosurgery again.

\subsection{Investigations}

CT scan showed intracranial pneumocephalus and the quantitative determination of glucose in nasal leakage was $4.5 \mathrm{mmol} / \mathrm{L}$. CT cisternography showed that the contrast agent flowed from the frontal sinus into the nasal cavity. (Fig. 2). The CSF collected from lumbar puncture showed normal results without any indication of intracranial infection.

\subsection{Diagnosis}

1. Delayed CSF rhinorrhea (fistula located in right frontal sinus).

2. Post-operation of bilateral anterior skull base reconstruction.

\subsection{Treatment}

The patient underwent craniotomy through the right trans-eyebrow approach. During the operation, the frontal sinus was found to be open, and no obvious epidural leakage was found near the frontal sinus. Further exploration of the anterior cranial base along the epidural was conducted, and the dural defect was found in the right cribriform plate, with a size of about $10 \star 10 \mathrm{~mm}$ (Fig. 3). We used a multi-layer reconstruction method with autologous fat and fascia to repair the leak. The patient was discharged on the 7th day.

\subsection{Outcome and Follow-Up}

At 6 months' follow-up, the patient had no CSF leakage, no intracranial infection, and could live a normal life.

\section{Discussion}

Traumatic CSF leakage occurs in $2 \%$ of head trauma patients, and accounts for $12-30 \%$ of all skull base fractures $^{[1]}$. Persistent CSF leaks often require surgical repair. Following repair, early recurrence can occur whereas the occurrence of delayed fistula is less common.

The qualitative diagnosis of CSF rhinorrhea is relatively simple,compared with the determination of sugar content ${ }^{[2,3]}$, the determination of beta-transferrin ${ }^{[4]}$, is more sensitive and specific. However, the difficulty lies in the determination of the location of CSF leakage, which is of great significance to clinical decisionmaking. The detction of bony defect is not difficult, and dural defect may be indicated by indirect signs. In most cases, the defects are contiguous. The most significant displacement of fracture slices are mostly the location of the fistula ${ }^{[5]}$. Patients with chronic traumatic CSF leakage can be inferred from the presence of meningeal encephalocele on MRI T2 images and abnormal accumulation of CSF ${ }^{[6]}$. CT 
cisternography is a good method to show the fistula. However, it has been noted that no imaging techniques are particularly useful ${ }^{[7]}$.In this case, CT cisternography ${ }^{[8]}$ suggests that the bony defect is in the frontal sinus. However, this method is static and does not dynamically show CSF flow,that is, the dural defect cannot be clearly shown. In this case, the dural defect was found to be non-contiguous with the bone fracture.

Delayed post-traumatic CSF rhinorrhea is more inclined to surgical treatment to reduce the risk of intracranial infection ${ }^{[9]}$. There are two kinds of surgical repair methods: craniotomy and transnasal approach $^{[10,11]}$. Common craniotomy incisions include unilateral frontal incision and bilateral frontal coronal incision ${ }^{[12]}$. It is suitable for patients with large skull base defects and extensive repairs, and for patients with frontal sinus opening. The transnasal approach is more suitable for those leakages in the sphenoid sinus, planum sphenoidale, tuberculum sellae, and the cribriform plate. These defects are generally small ${ }^{[13]}$. Therefore, identifying the fistula, including dural and bony defects is the most important task.

In this case, the fistula was considered to be in the frontal sinus. Considering that the blood supply of the pedicle could have been compromised if the original incision had been taken. Hence,we chose the transeyebrow incision to expose the defects. This minimally invasive approach is widely used in the resection of lesions in the anterior skull base ${ }^{[14-17]}$, including tumors and aneurysms. It can effectively expose the bone and the dura of the anterior skull base, and is feasible for the exploration and repair of the bony and dural defects. Unexpectedly, the dural and bony defects are discontinous, and the choice of transnasal repair may lead to the failure of the operation. To analyze the causes of inconsistent fistula,we infer that the anterior skull base was covered with pedicled temporoparietal fascial flaps in the first operation, thus the bony defect was repaired, while the dural defect perhaps remained patent. Delayed CSF leakage may occur when the frontal sinus was not closed properly or when the bone wax contracted and displaced ${ }^{[18]}$. This case also suggests that the sealing of the frontal sinus may not be sufficient with bone wax alone, but pedicled periosteal flaps may be required. Since there is no pedicled vascular tissue available for the second operation, we chose free fat and fascia for multilayer repair, which proved to be reliable.

\section{Conclusions}

This case suggests that delayed traumatic CSF rhinorrhea after reconstructive surgery is more complex than usual,CT cisternography is not reliable,especially for identifying the dural defect,and appropriate approach should be adopted to repair the dural and bony defects, the transeyebrow approach is a good choice.

\section{Abbreviations}

CSF 
Cerebrospinal fluid; CT:Computed tomography; GCS:Glasgow Coma Scale;MRI:Magnetic resonance imaging

\section{Declarations}

\section{Acknowledgements}

Not applicable.

\section{Authors' contributions}

Xiaofei Liu and Ping Chen participated in the treatment of this patient with assistance from Bing Wang and was involved in the development of the conclusions. Bing Wang wroteand edited the draft. All authors had read and approved the final manuscript.

\section{Funding}

This work was supported by grants from the Natural Science Foundation of Hunan province (2018JJ3461).

\section{Availability of data and materials}

Not applicable.

\section{Ethics approval and consent to participate}

Not applicable.

\section{Consent for publication}

Written informed consent for publication of the clinical details and clinical images was obtained from the patient.

\section{Competing interests}

The authors declare that they have no competing interests.

\section{Author details}


1Department of Neurosurgery, The Second Hospital, University of South China,Hengyang 421001, China.

\section{References}

1. Friedman JA, Ebersold MJ, Quast LM. Persistent posttraumatic cerebrospinal fluid leakage. Neurosurg Focus. 2000;9(1):e1.

2. Ziu M, Savage JG, Jimenez DF. Diagnosis and treatment of cerebrospinal fluid rhinorrhea following accidental traumatic anterior skull base fractures. Neurosurg Focus. 2012;32(6):E3.

3. Oakley GM, Alt JA, Schlosser RJ, Harvey RJ, Orlandi RR. Diagnosis of cerebrospinal fluid rhinorrhea: an evidence-based review with recommendations. Int Forum Allergy Rhinol. 2016;6(1):8-16.

4. Mantur M, Łukaszewicz-Zając M, Mroczko B, et al. Cerebrospinal fluid leakage-reliable diagnostic methods. Clin Chim Acta. 2011. 412(11-12): 837 - 40.

5. Reddy M, Baugnon K. Imaging of Cerebrospinal Fluid Rhinorrhea and Otorrhea. Radiol Clin North Am. 2017;55(1):167-87.

6. Bonetto N, Manara R, Citton V, Cagnin A. Spinal subtraction MRI for diagnosis of epidural leakage in SIH. Neurology. 2011;77(21):1873-6.

7. Kranz PG, Tanpitukpongse TP, Choudhury KR, Amrhein TJ, Gray L. Imaging Signs in Spontaneous Intracranial Hypotension: Prevalence and Relationship to CSF Pressure. AJNR Am J Neuroradiol. 2016;37(7):1374-8.

8. Nursal GN, Yapar AF. Demonstration of cerebrospinal fluid leakage on radionuclide cisternography by SPECT/CT. Clin Nucl Med. 2015;40(1):e55-7.

9. Liao KH, Wang JY, Lin HW, et al. Risk of death in patients with post-traumatic cerebrospinal fluid leakage-analysis of 1773 cases. J Chin Med Assoc. 2016;79(2):58-64.

10. Liu P, Wu S, Li Z, Wang B. Surgical strategy for cerebrospinal fluid rhinorrhea repair. Neurosurgery. 2010;66(6 Suppl Operative):281-5. discussion 285-6.

11. Kreatsoulas DC, Shah VS, Otto BA, Carrau RL, Prevedello DM, Hardesty DA. Surgical outcomes of the endonasal endoscopic approach within a standardized management protocol for repair of spontaneous cerebrospinal fluid rhinorrhea. J Neurosurg. 2020: 1-7.

12. Safavi-Abbasi S, Komune N, Archer JB, et al. Surgical anatomy and utility of pedicled vascularized tissue flaps for multilayered repair of skull base defects. J Neurosurg. 2016;125(2):419-30.

13. Clavenna MJ, Turner JH, Chandra RK. Pedicled flaps in endoscopic skull base reconstruction: review of current techniques. Curr Opin Otolaryngol Head Neck Surg. 2015;23(1):71-7.

14. Reisch R, Marcus HJ, Hugelshofer M, Koechlin NO, Stadie A, Kockro RA. Patients' cosmetic satisfaction, pain, and functional outcomes after supraorbital craniotomy through an eyebrow incision. J Neurosurg. 2014;121(3):730-4.

15. Chiappini A, Marchi F, Reinert M, Robert T. Supraorbital approach through eyebrow skin incision for aneurysm clipping: how I do it. Acta Neurochir (Wien). 2018;160(6):1155-8. 
16. He H, Li W, Liang C, et al. Eyebrow Incision for Combination Supraorbital Minicraniotomy with Orbital Osteotomy: Application to Cranio-Orbital Lesions. World Neurosurg. 2018;114:e631-40.

17. Lee YM, Park HJ, Kim SD, Cho KS. Mini Osteoplastic Flap Through Supra-Eyebrow Incision for Primary Frontal Sinus Squamous Cell Carcinoma. J Craniofac Surg. 2020;31(2):517-9.

18. Das JM. Bone Wax in Neurosurgery: A Review. World Neurosurg. 2018;116:72-6.

\section{Figures}
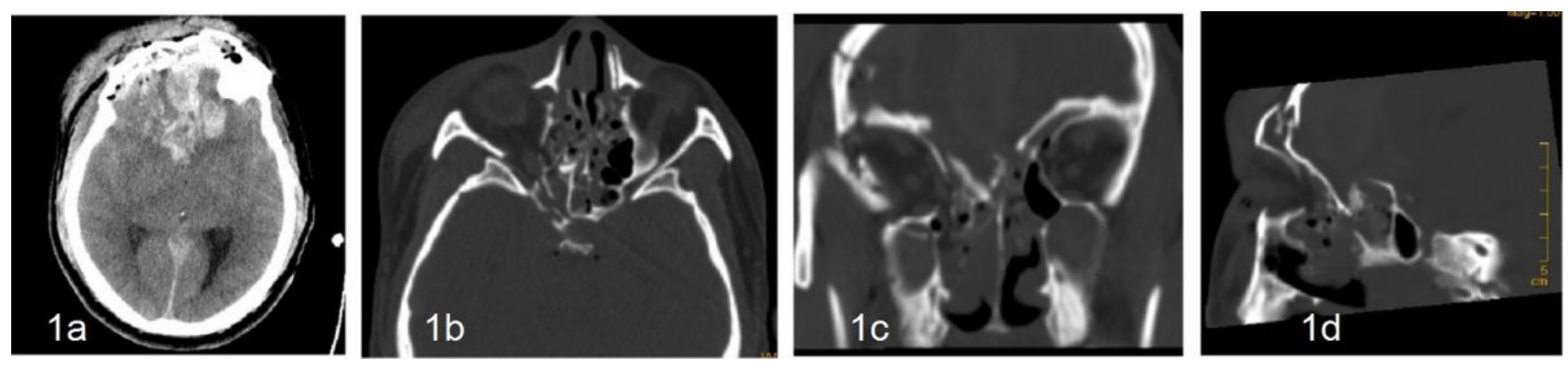

Figure 1

CT scan before the first operation.1a shows contusion and laceration of bilateral frontal lobe with hematoma formation, $1 \mathrm{~b}-1 \mathrm{~d}$ show comminuted fracture of frontal bone and anterior skull base, especially on the right side.
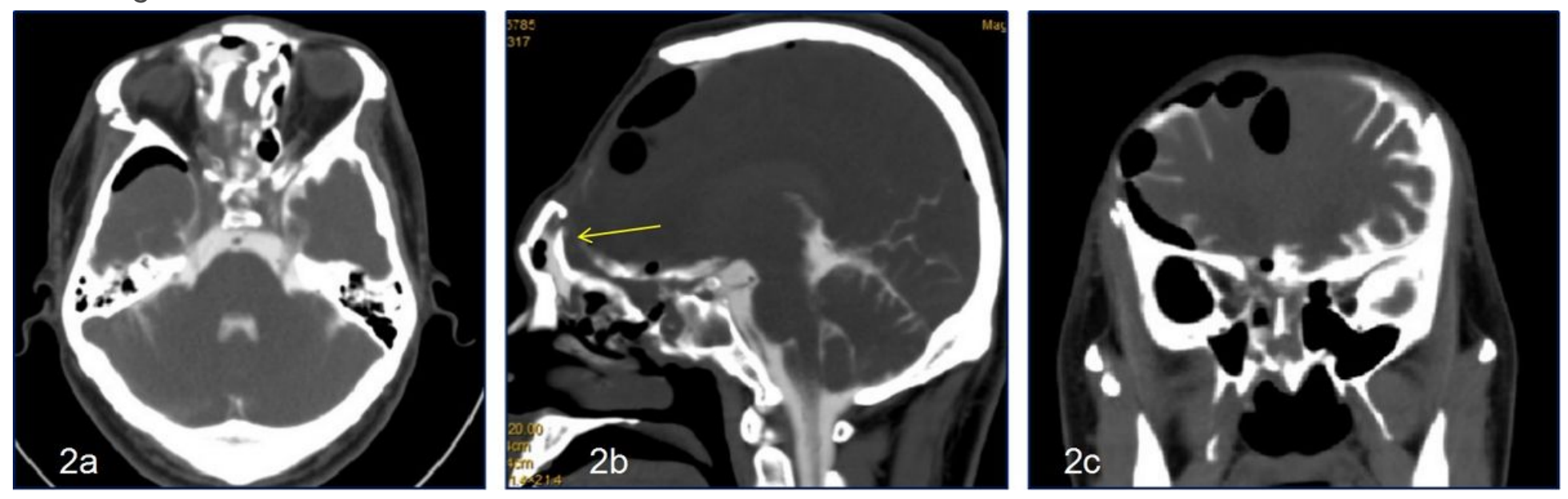

Figure 2

Image of CT Cisternography.CT cisternography shows contrast agent leaks from right frontal sinus to nasal cavity.The arrow in figure $2 b$ shows a leak of contrast material from the frontal sinus. 


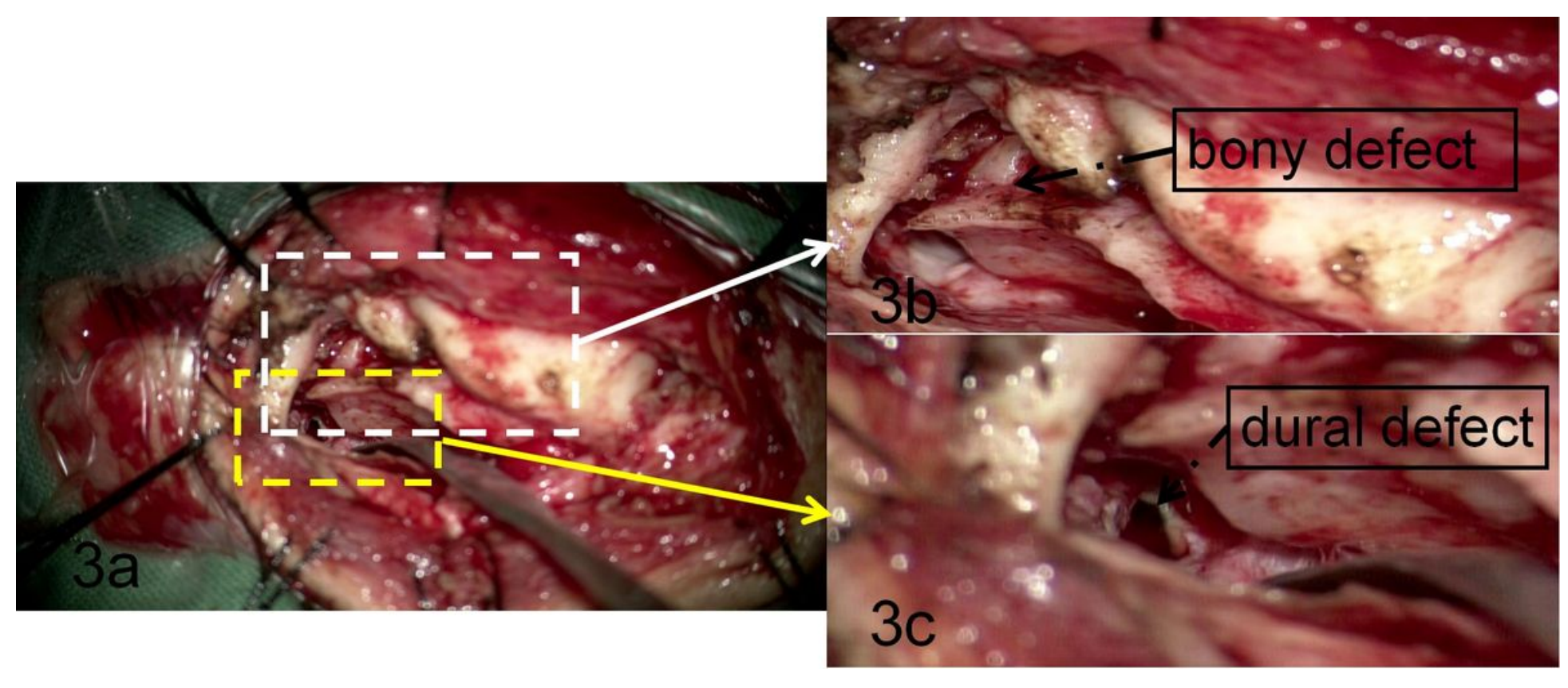

Figure 3

Screenshot of the second operation video.The right transeyebrow approach was used.3a shows the intraoperative exploration of CSF leakage. $3 b$ and $3 c$ show bony and dural defect, respectively. 